\title{
EDITORIAL
}

\section{The promise of electronic data capture in respiratory medicine}

\author{
N. Johnston, P. O’Byrne and M. Kolb
}

( $\mathrm{n}$ the 17th century the English physician John Floyer, himself severely asthmatic, used symptom diaries to record his own and his patients' symptoms to understand the determinants of asthma exacerbations, and inform disease management [1]. If long-term serial data on designated patients with chronic lung disease were available to physicians, it could fundamentally change clinical practice and influence the design of clinical research studies. However, methods of symptom diary data collection that frustrate patients and which require analysis by physicians before interpretation are unlikely to achieve broad success. A recent editorial in the European Respiratory Journal [2] drew attention to the emphasis, in current guidelines for asthma management [3] and in the conduct of clinical trials in asthma [4], of the importance of estimating "future risk" to patients. The concept has equal relevance in other chronic lung diseases. Guidances issued by both the European Medicines Agency and the US Food and Drug Administration [5, 6] have contemplated and encouraged the adoption of patient reported outcomes (PROs) in chronic disease research.

The report by LIU et al. [7] in the current issue of the European Respiratory Journal describes the experimental evaluation of a mobile telephone-based system compared with a paper diary for monitoring the management of adult asthmatics, and found significant clinical improvements in the electronically monitored patients. As noted in a recent meta-analysis of studies of electronic patient-reported symptom monitoring in respiratory disease [8], there are as yet an inadequate number of published reports of studies with robust designs and formal evaluation in this area, and the study by LiU et al. [7] is a welcome addition. The approach taken to symptom diary data collection was inexpensive and used technologies that are becoming almost universally available.

Importantly, this study also showed good patient compliance with data provision in a contemporary clinical practice. In our own research studies of chronic obstructive pulmonary disease (COPD) patients, we have observed compliance with electronic PRO provision over a $1-y r$ period exceeding 98\% using BlackBerry smartphones [9] and over 95\% using an earlier fax based system [10].

McMaster University, Firestone Institute for Respiratory Health, Hamilton, ON, Canada.

CORRESPONDENCE: M. Kolb, Depts of Medicine, Pathology and Molecular Medicine, McMaster University, Firestone Institute for Respiratory Health, 50 Charlton Ave East, Room T2121, Hamilton, ON, L8N 4A6, Canada. E-mail: kolbm@mcmaster.ca
Audits of well-conducted studies of COPD which used paperbased diaries and/or reliance on study subjects to report possible COPD exacerbations have shown that they achieved detection of only one-third to one-half of these at their inception [11-14]. Such under-detection of categorical study events through low patient self-report rates may compromise the generalisability of study findings to the population at risk. It may also reduce study efficiency, lengthen their time to completion [4] and potentially delay regulatory approval of therapies. Using electronic PROs we found that of 111 acute exacerbations occurring in a cohort of COPD patients over a 5month period, only one was not detected at inception [10].

With paper-based symptom diaries in studies of respiratory diseases, a more sinister finding has been that significant numbers of subjects falsify data $[15,16]$, and that the likelihood of this occurring increases with the length of the study period. In a randomised trial of electronic symptom recording versus monitored paper-based recording, actual compliance was $94 \%$ in the "electronic" group, while faked compliance with paperbased recording was 73\% [17].

In a clinical setting, as in the LiU et al. [7] study, cost considerations may dictate the use of technologies for PROs with cheap mass availability, whereas in research, particularly clinical trials, more stringent requirements for data control and standardisation of methods may dictate the use of more sophisticated technologies. In both cases a number of design and operational considerations may influence success.

While in the case of asthma many patients are young, dexterous and have unimpaired faculties, this may not be the case with other chronic respiratory diseases. Patients, no matter how high their level of commitment, who are presented with a data entry process that they have difficulty comprehending and completing are unlikely to comply with it. Our experience in the design of electronic PROs suggests that entry of data should be accomplished as simply as possible, preferably using only a single trackpad or similar device, and should avoid the use of keyboards or other devices such as pointers; poor visual acuity may be compensated for through selection of devices with bright clear high-contrast screens, careful font selection and judicious use of colour, shading and highlights; individual questions should be easily distinguishable from each other through such mechanisms as loading one question per screen, numbering questions and providing a sequence of two distinct backgrounds; patients should be notified if they have missed a question and also be able to 
check their responses before sending a completed questionnaire.

Voice recognition technology has advanced significantly in recent years and access to either cellular or wired telephones is near universal. While the value of this technology for the collection of PROs will need to be formally evaluated, it offers significant promise at a low cost and will be of particular value when patients have a high prevalence of impaired visual acuity or poor dexterity.

E-mail questionnaires sent to patients have the advantage of low cost and may be an ideal method for collection of PROs from those patients who are equipped with computers and email accounts; however this is possibly less likely in low socioeconomic groups who may be at higher risk of uncontrolled disease. Furthermore, the array of different types and ages of computer equipment likely to be encountered in a patient population may raise complex technical issues and increase the levels of support that need to be provided by staff.

The use of general packet radio service for PRO data collection used for asthma patients by LIU et al. [7] has advantages over other approaches, notably low cost, but may be less feasible in patients with chronic lung diseases in whom the majority are elderly and may have impaired vision and dexterity.

Patients with chronic lung disease, particularly the elderly, confronted for the first time by a request to serially enter data, may experience a lack of confidence that they will be able to use the data collection device. That confidence will be gained through the use of high-quality, well-engineered and pretested devices for data entry; patient and thorough instruction by clinical/study staff, which incorporates the presentation of scenarios for different data entry situations; and assurance that if devices or systems malfunction the patient is not to blame and the problem will be addressed.

During electronic PRO collection, patients should receive automatic feedback to confirm when data have been successfully transmitted. Compliance should be carefully monitored and staff should automatically be notified when data have not been received from a given patient for two sequential data entries. PRO questionnaires should include an open question asking patients if they would like staff to contact them. Once transmitted, PRO data for each subject should be integrated into a readily accessible record for each subject with preassigned flags set to notify staff when changes of interest occur.

Patients quite reasonably expect their health information to be treated with confidence. While the likelihood of PRO data being maliciously copied by unauthorised individuals may be low, patients may be more likely to provide their data electronically or participate in research studies using electronic PRO capture if they are confident that their data will be secure.

Neither cellular nor wired telephones are technically secure, but illicit capture of data from individual patients would require intervention at the level of the patient's telephone. Data transmitted by e-mail can be encrypted, as can data transmitted using some Smart phones. PRO data capture systems that are fully secure raise costs significantly and in the case of broad-based systems for clinical application these may not be justifiable. However, in research studies, institutional review boards or regulatory bodies may require PRO data encryption as may companies providing funding. In addition, recruitment may be enhanced if patients can be assured that their data will only be seen by authorised study staff.

Realisation of the benefits of using PRO data in broad clinical practice has not been feasible until the advent of almost universal availability of electronic data transmission. The potential to add serial data reported by respiratory patients directly to the medical record in real time can permit more effective patient monitoring and enable the onset of disease exacerbations to be detected at their inception, particularly when clinical or research staff are automatically alerted when significant changes in a patient's health occur.

In clinical research of chronic respiratory diseases, electronic PRO collection has the potential to both shorten the length of studies through efficient data management and introduce sensitive study outcomes based on continuous patient data as a possible alternative to the use of arbitrary categorical events.

Further well-conducted clinical trials of the value of electronic $\mathrm{PRO}$ in the long-term management of chronic lung diseases, including economic analyses should be a research priority.

\section{STATEMENT OF INTEREST}

A statement of interest for N. Johnston can be found at www.erj. ersjournals.com/site/misc/statements.xhtml

\section{REFERENCES}

1 Floyer JA. A Treatise of the Asthma. 2nd Edn. London, R. Wilkin and W. Innys, 1717.

2 Taylor DR. An eye to the future: exhaled nitric oxide as a predictor of clinical outcomes in asthma. Eur Respir J 2010; 35: 1200-1202.

3 Expert Panel Report 3 (EPR-3), Guidelines for the Diagnosis and Management of Asthma-Summary Report 2007. I Allergy Clin Immunol 2007; 120: Suppl. 5, S94-S138.

4 Reddel HK, Taylor DR, Bateman ED, et al. An official American Thoracic Society/European Respiratory Society statement: asthma control and exacerbations: standardizing endpoints for clinical asthma trials and clinical practice. Am J Respir Crit Care Med 2009; 180: 59-99.

5 European Medicines Agency, Committee for Medicinal Products for Human Use (CHMP). Reflection paper on the regulatory guidance for the use of health-related quality of life (HRQL) measures in the evaluation of medicinal products. London, EMEA/CHMP/ EWP/139391/2004, 2005. www.ema.europa.eu/ema/pages/includes/ document/open_document.jsp?webContentId=WC500003637 Date last accessed: November 30, 2010. Date last updated: July 27, 2005.

6 Guidance for Industry Patient-Reported Outcome Measures: Use in Medical Product development to support Labeling Claims. U.S. Department of Health and Human Services, Food and Drug Administration, Center for Drug Evaluation and Research (CDER), Center for Biologics Evaluation and Research (CBER), Center for Devices and Radiological Health (CDRH), 2009. www.fda.gov/ downloads/Drugs/GuidanceComplianceRegulatoryInformation/ Guidances/UCM193282.pdf Date last accessed: November 30, 2010. Date last updated: December 2009.

7 Liu W-T, Huang C-D, Wang C-H, et al. A mobile telephone-based interactive self-care system improves asthma control. Eur Respir J 2011; 37: 310-317.

8 Jaana M, Pare G, Sicotte C. Home telemonitoring for respiratory conditions: a systematic review. Am J Manag Care 2009; 15: 313-320. 
9 Johnston N, McIvor RA, Lambert $\mathrm{K}$, et al. Evaluation of the effectiveness of fax and BlackBerry based symptom diaries for daily monitoring of COPD patients. Eur Respir J 2008; 32: Suppl. 52, $661 \mathrm{~s}$.

10 Johnston NW, McIvor RM, Lambert K, et al. The Christmas season as a risk factor for COPD exacerbations. Can Respir J 2010; 17: 275-281.

11 Miravitlles M, Ferrer M, Pont A, et al. Effect of exacerbations on quality of life in patients with chronic obstructive pulmonary disease: a two year follow up study. Thorax 2004; 59: 387-395.

12 Langsetmo L, Platt RW, Ernst P, et al. Underreporting exacerbations of chronic obstructive pulmonary disease in a longitudinal cohort. Am J Respir Crit Care Med 2007; 177: 396-401.
13 Vijayasaratha K, Stockley RA. Reported and unreported exacerbations of COPD - analysis by diary cards. Chest 2007; 133: 33-41.

14 Burge S, Wedzicha JA. COPD exacerbations: definitions and classifications. Eur Respir J 2003; 21: Suppl. 41, 46S-53S.

15 Cote J, Cartie A, Malo J-L, et al. Compliance with peak expiratory flow monitoring in home management of asthma. Chest 1998; 113: 968-972.

16 Chowienczyk PJ, Parkin DH, Lawson CP, et al. Do asthmatic patients correctly record home spirometry measurements? BMJ 1994; 309: 1618-1620.

17 Stone AA, Shiffman S, Schwartz JE, et al. Patient compliance with paper and electronic diaries. Controlled Clinical Trials 2003; 24: 182-199. 